\title{
Meditation and Positive Mental Health
}

\section{Balaji Deekshitulu PV}

Psychologist\& Alternative Medicine (Homeopathy) Practitioner, Sri Balaji Clinic, Tirupati, A.P, India

"Corresponding author: Balaji Deekshitulu PV, Psychologist \& Alternative Medicine (Homeopathy) Practitioner, Sri Balaji Clinic, Tirupati, A.P, India. Tel: +918885391722, +917207255557;E-Mail:drsribalaji@gmail.com

Citation: Balaji Deekshitulu PV (2017) Meditation and Positive Mental Health. J Psychiatry Cogn Behav 2: 108. DOI: 10.29011/2574-7762.000008

Received Date: 4 April2017; Accepted Date: 10 May, 2017; Published Date: 23 May, 2017

\begin{abstract}
In the review of study Meditation is a relaxation technique that involves mostly the mind, which in turn affects the physical body as well. This technique can be used as a stress reducer. In stilling your mind and body, you can forget for a short period the many trials of the day. Studies have shown that meditation can have beneficial effects on the health of the body as well as positive results in stress reduction levels, and get back in to balance, step back, and get refreshed and emerged so it can go back to productive lifestyle.
\end{abstract}

Keywords: Asanas; Meditation; Mental health; Types of Meditation

\section{Introduction}

Meditation is an ancient technique to revive your weary soul and help you deal effectively with stress, and helps you rediscover a sense of profound peace and inner calmness., Meditation one of the eight limbs of yoga outlined in Patanjali`s Yoga Sutra, The great seer has described yoga as-yogas chittavrittinirodhah, which means completely shutting out all kinds of mental fluctuations. When such a stage is reached, meditation (dyana) is perfected, resulting in yoga (union of individual consciousness with the cosmic consciousness) that is the zenith of meditation.

According to Swami Vishnu Devananda, meditation is “.... a continuous flow of perception or thought, just like the flow of water in a river." It helps you dig deep into your inner self to discover the wisdom and tranquility that lie within. Meditation is a relaxation technique that involves mostly the mind, which in turn affects the physical body as well. This technique can be used as a stress reducer. In stilling your mind and body, you can forget for a short period the many trials of the day. Studies have shown that meditation can have beneficial effects on the health of the body as well as positive results in stress reduction levels. There are several ways to meditate there are...

\section{Types of Meditation}

Guided Visualization: Guided visualization is a newer technique that can be used for spiritual healing, stress relief, or personal development. The inspiration comes from Buddha, "The mind is everything. What you think you become."Among other factors that set this form of meditation apart, the emphasis on one specific goal is defining. By imagining relaxing and positive experiences, the body will respond by releasing chemicals that generate feelings of positivity.

Transcendental Meditation (TM): "The goal of Transcendental Meditation is the state of enlightenment. This means we experience that inner calmness, that quiet state of least excitation, even when we are dynamically busy." In this Hindu tradition, you sit in Lotus, internally chant a mantra, and focus on rising above the negativity.

Heart Rhythm Meditation (HRM): This is focuses energy on developing the application of consciousness. This meditation concentrate on the heart, with an emphasis on breathing, and the purpose is to experience the mystics" mantra, "I am a part of all things and all things are a part of me."

Kundalini: Kundalini focuses on the rising stream of energy. This form of meditation has roots in both Buddhist and Hindu teachings, and in Sanskrit translates to 'Coiled'. Many believe this to be a metaphoric form of mediation, however those who are able to access the dormant energy can attest to its healing benefits. To access this energy the individual must concentrate on their breathing as it flows through the energy centres in the body. Once that energy is felt, the individual can experience an altered state of consciousness.

Qi Gong: This is a meditation favourite because this method improves posture, respiration, and the ability to relax with greater ease. Qi Gong is one of the oldest forms of meditation and derives 
from ancient Chinese society. This art form of health and wellness uses breath to circulate energy through the body and energy centres. The focused combination on breathing techniques, movement, and meditation helps the individual to control their reactions to stress.

Tai chi: This is a form of gentle Chinese martial arts. In tai chi (TIE-chee), you perform a self-paced series of postures or movements in a slow, graceful manner while practicing deep breathing.

Mindfulness meditation: This type of meditation is based on being mindful, or having an increased awareness and acceptance of living in the present moment. You focus on what you experience during meditation, such as the flow of your breath. You can observe your thoughts and emotions but let them pass without judgment.

Zazen: This is "Seated Meditation". This method is initially the easiest to engage in because it relies on self-guidance; however, the lack of guidance can make it difficult to progress in the future. Regardless, the mental benefits of Zazen are vast because you aim to forget all judgmental thoughts, ideas, and images. After sitting in a comfortable position ensure that the back is completely straight and you are centered. Breathing is an essential element of Zazen and this position will allow the breath to deepen and enhance the experience.

Mantra Meditation (OM Meditation): A mantra is a syllable or word, usually without any particular meaning, that is repeated for the purpose of focusing your mind. Mantra to the "vibration" associated to the sound and meaning. Mantra itself is only a tool to focus the mind, and the chosen word is completely irrelevant.

Third Eye Meditation: focusing the attention on the "Spot Between the Eyebrows" (called by some "The Third Eye" or "Ajna Chakra"). The attention is constantly redirected to this point, as a means to silence the mind. By time the "silent gaps" between thoughts get wider and deeper. Sometimes this is accompanied by physically "looking", with eyes closed, towards that spot.

Chakra Meditation: the practitioner focuses on one of the seven chakras of the body ("Centres of Energy"), typically doing some visualizations and chanting a specific mantra for each chakra (lam, vam, ram, yam, ham, om). Most commonly it is done on the heart chackra, third eye, and crown chackra.

Sound Meditation (Nada Yoga): focusing on sound the meditation on "External Sounds", such as calming ambient music (like classical or instrumental music), as a help to quieten and collect the mind. By time the practice evolves to hearing the "Internal Sounds" of the body and mind. The ultimate goal is to hear the "Ultimate Sound" (para nada), which is a sound without vibration, and that manifests as "OM".

Tantra: Tantra practices have nothing to do with ritualized sex (this was practiced by a minority of lineages. Tantra is a very rich tradition, with dozens of different contemplative practices.

Pranayama: breathing regulation. It is not exactly meditation, but an excellent practice to calm the mind and prepare it for meditation. There are several different types of Pranayama, but the simplest and most commonly taught one is the 4-4-4-4. This means breathing in counting up to 4 , holding for 4 seconds, breathing out for 4 seconds, and holding empty for 4 seconds. Breathe through your nose, and let the abdomen (and not the chest) be the one that moves. Go through a few cycles like this. This regulation of breathing balances the moods and pacifies the body, and can be done anywhere. agree of stillness and mind control).

Meditative Asanas: These asanas provide a comfortable and stable position of the body to make the mind more and more study for the process of meditation. Padmasana, Sidhhasana and Swastikasana are few relaxative asanas.

\section{Benefits of Mental Health}

- $\quad$ Reduce Stress

- Boost Happy Chemicals

- Improve Self-Confidence

- Prevent Cognitive Decline

- Alleviate Anxiety

- Boost Brainpower

- Sharpen Memory

- Help Control Addiction

- Increase Relaxation

Michael McGee (2008) indicated that the nature of meditation and its therapeutic benefits. It then concludes with a summary of the issues pertinent to the adjunctive use of meditation in psychiatric care [1]. Masud Yunesian (2008)suggested that the Transcendental Meditation may improve mental health of young adult population especially in the areas of somatisation and anxiety, and this effect seems to be independent of age, sex and marital status [2].

Yang KP (2009) studied that the Meditation can help students to adapt to life stressors. This study also provides support for traditional Chinese wisdom, which promotes meditation as one way to improve health [3].

Beth Cholette,(2010) reviewed that Ana Brett \& Ravi Singh, Kundalini Yoga Solar Power All-In-One Workout, Kundalini yoga, it is important to understand that it differs from what is usually called hatha yoga; it is generally more dynamic, and the Breath of Fire is a unique component, the exercises are challenging yet doable and that it includes a singing mantra meditation. Solar Power should certainly appeal to existing fans of this husband/wife team, and I would also recommend it to those with some prior hatha yoga experience who are interested in trying Kundalini for the first time [4]. 
Cutshall, Susanne M, et al. (2011) reported that computerguided meditation program, and found significant improvement from baseline in stress management [5]. Britta K, et al. (2011) reported that brain analyses identified increases in the posterior cingulate cortex, the temporo-parietal junction, and the cerebellum in the Mindfulness-Based Stress Reduction (MBSR) group compared with the controls. The results suggest that participation in MBSR is associated with changes in gray matter concentration in brain regions involved in learning and memory processes, emotion regulation, self-referential processing, and perspective taking [6].

Amit Mohan, et al. (2011) reported that study consisted of practicing 20 minutes of guided meditation was associated with relaxation and a decrease in markers of stress. Meditation, if practiced before the stressful event, reduced the adverse effects of stress [7]. Josefsson, Torbjörn, et al. (2011) reported that an indirect effect of meditation experience on psychological wellbeing via the five mindfulness facets. that length of meditation experience is related to higher levels of mindfulness, which in turn is associated with improved well-being.

Manocha R, (2011) reported that Mental silence-orientated meditation, in this case Sahaja Yoga meditation, is a safe and effective strategy for dealing with work stress and depressive feelings [8]. Shauna L Shapiro, et al. (2012) suggested that the main goals of meditation, to uncover the positive and to catalyze our internal potential for healing and development,Geoffrey W. Melville, et al. (2012) reported that meditation performed in the office can acutely improve several physiological and psychological markers of stress. These effects may be at least partially mediated by reduced respiration rate $[9,10]$.

David M. Levy, et al. (2012) reported that less negative emotion after task performance, as compared with the other two groups. In addition, both the meditation and the relaxation groups showed improved memory for the tasks they Amy G Lam, et al.(2015) explain that the five-minute mindfulness meditation could be an effective method in decreasing stress in this mental health care professional sample $[11,12]$.

Naved Iqbal (2015) suggested that the positive self-evaluation, perception of reality and group-oriented attitude dimensions of mental health in post-condition. Overall, dynamic meditation training was effective in improving mental health of the subjects [13]. Kusuma (2016)indicated that the practice of yoga-meditation is strongest foundation for building the base of one's positive mental health [14].

Goyal M, et al.(2016)report that the emotional well-being, happiness and self-realization. Yoga, among other activities, is in line with this new view, in the sense that it practices key aspects of positive psychology,Marina A. Khusid and Meena Vythilingam (2016) suggested that the mindfulness-based stress reduction is effective for improving symptoms, mental health-related quality of life, and mindfulness in veterans with combat post-traumatic stress disorder $[15,16]$.

\section{Conclusion}

Meditation was found to be effective in increasing self-actualization-an overall measure of positive mentalhealth and personal development. Meditation will keep you healthy, help prevent multiple diseases, make you happier, and improve your performance in basically any task, physical or mental in meditation has been found to improve mental health by reducing biochemical indicators of stress, decreasing anxiety, and enhancing psychological development.

\section{References}

1. McGee $\mathrm{M}(2008)$ Meditation and Psychiatry. Psychiatry (Edgmont) 5: 28-41.

2. Yunesian M, AslaniA, Vash JH, Yazdi AB (2008) Effects of Transcendental Meditation on mental health: a before -after study. Clinical Practice and Epidemiology in Mental Health 4:25.

3. Yang KP, Su WM, Huang CK (2009)The effect of meditation on physical and mental health in junior college students. J Nurs Res 17:261-269.

4. Cholette B (2010) Kundalini Yoga Solar Power All-In-One Workout. http://www.veridianbh.com.

5. Cutshall SM, Wentworth LJ, Wahner-Roedler DL, Vincent A, Schmidt JE, et al. (2011) Evaluation of a biofeedback-assisted meditation program as a stress management tool for hospital nurses. The Journal of Science and Healing 7: 110-112.

6. Holzel BK, Carmody J, Vangel M, Congleton C, Yerramsetti SM, et al. (2011) Mindfulness practice leads to increases in regional brain gray matter density. Pschyiatry Res 191: 36-43.

7. Mohan A, Sharma R, Bijlani RL (2011) Medicine Effect of Meditation on Stress-Induced Changes in Cognitive Functions. The Journal of Alternative and Complementary 17: 207-212.

8. Manocha R, Black D, Sarris J, Stough C (2011) A Randomized, Controlled Trial of Meditation for Work Stress, Anxiety and Depressed Mood in Full-Time Workers. Evidence-Based Complementary and Alternative Medicine: 1-8.

9. Shapiro SL, Schwartz GER, Santerre C (2012) Meditation and positive psychology.

10. Melville GW, Chang D, Colagiuri B, Marshall PW, Cheema BS (2012) Fifteen Minutes of Chair-Based Yoga Postures or Guided Meditation Performed in the Office Can Elicit a Relaxation Response. EvidenceBased Complementary and Alternative Medicine 2012: 1-9.

11. Levy DM, Wobbrock JO, Kaszniak AW, Ostergren M (2012) The Effects of Mindfulness Meditation Training on Multitasking in a HighStress Information Environment. Graphics interface 2012: 45-51.

12. Lam AG, Sterling S, Margines E (2015) Effects of Five-Minute Mindfulness Meditation on Mental Health Care Professionals. J PsycholClin Psychiatry 2: 1-6.

13. Iqbal N, Singh A, Aleem S (2015) Effect of Dynamic Meditation on Mental Health. Journal of Religion and Health 55: 241-254. 
Citation: Balaji Deekshitulu PV (2017) Meditation and Positive Mental Health. J Psychiatry Cogn Behav 2: 108. DOI: 10.29011/2574-7762.000008

14. Kusuma A (2016) Yoga-meditation and positive health. Innovare Journal Health Science 4: 14-17.

15. Goyal M, Singh S, Sibinga EM, Gould NF, Rowland-Seymour A, et al.(2014) Meditation programs for psychological stress and well-being. JAMA Intern Med 174:357-368.
16. Khusid MA, Vythilingam M (2016) The Emerging Role of Mindfulness Meditation as Effective Self-Management Strategy, Part 1: Clinical Implications for Depression, Post-Traumatic Stress Disorder, and Anxiety. Mil Med181: 961-968. 